\title{
2-mercaptobenzimidazole films formed at ultra-low pressure on copper: adsorption, thermal stability and corrosion inhibition performance
}

\author{
Xiaocui Wu, Frédéric Wiame*, Vincent Maurice, Philippe Marcus* \\ Université PSL, CNRS - Chimie ParisTech, Institut de Recherche de ChimieParis, \\ Physical Chemistry of Surfaces Group, 75005 Paris, France
}

\begin{abstract}
2-mercaptobenzimidazole (2-MBI) is considered as an effective corrosion inhibitor for copper. In this study, the adsorption of 2-MBI on pristine and pre-oxidized $\mathrm{Cu}(111)$ surfaces was investigated by sublimation at ultra low pressure, using Auger Electron Spectroscopy, Scanning Tunneling Microscopy and X-ray Photoelectron Spectroscopy in order to understand its corrosion inhibition properties. 2-MBI adsorbs with $\mathrm{S}$ and $\mathrm{N}$ atoms bonded to $\mathrm{Cu}$. On pristine $\mathrm{Cu}(111)$ surface, a self-assembled monolayer is formed at about $5 \mathrm{~L}$, with the adsorption of atomic S resulting from molecule decomposition to form a $(\sqrt{7} \times \sqrt{7}) \mathrm{R} 19.1^{\circ}$ structure, and that of the molecule forming a $(8 \times 8)$ structure. 2 -MBI is lying flat in the adsorbed multilayer. Oxidation of copper prior to exposure results in compact and homogeneous molecular films, with dissociation and substitution of $2 \mathrm{D}$ oxide by $2-\mathrm{MBI}$, but much more slower than that for 2-mercaptobenzothiazole (2-MBT). A multilayer of 2-MBI can block the initial stages of oxidation of copper under low oxygen pressure at room temperature, and the molecular layer is stable until $500^{\circ} \mathrm{C}$. The comparison with 2-MBT suggests that the latter is a better corrosion inhibitor for copper at room temperature.
\end{abstract}

Keywords: 2-MBI, Corrosion inhibition, Copper, STM, AES, XPS

\footnotetext{
*Corresponding authors

Email addresses: frederic.wiame@chimieparistech.psl.eu (Frédéric Wiame), philippe.marcus@chimieparistech.psl.eu (Philippe Marcus)
} 


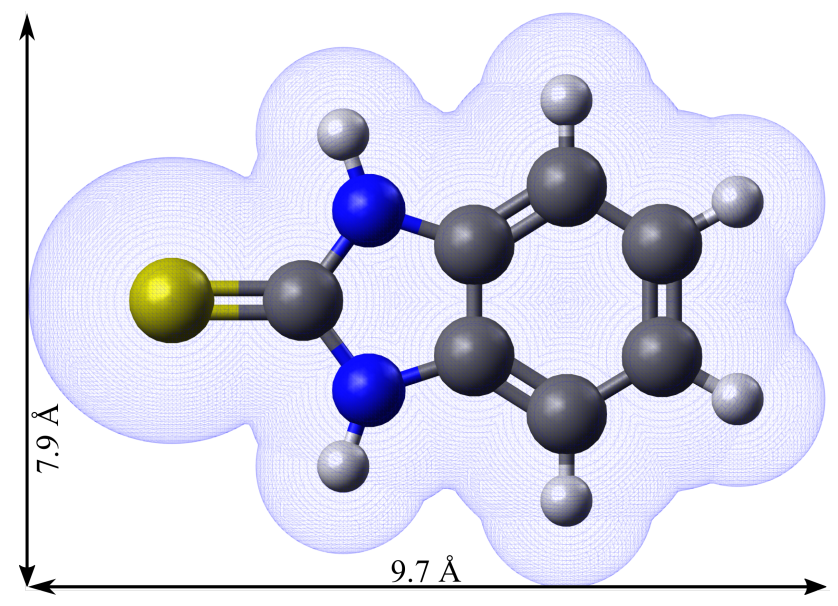

Figure 1: 2-MBI chemical structure (thione form) and associated molecular dimensions (the van der Waals surface is presented).

\section{Introduction}

Corrosion is one of the main causes of alteration and destruction of most facilities and equipments. Copper corrosion can cause huge economic losses due to the wide applications of copper and copper alloys in the industrial, military and civilian sectors, and thus it is particularly important to find a way to limit that phenomenon. The use of corrosion inhibitor has been proven to be an effective approach to control the corrosion of metals and alloys which are in contact with aggressive environments [1-5].

It is commonly believed that, for inhibition to function, adsorption of the inhibitory molecules on the substrate surface must take place, that the interaction must be strong and that a protective film must be formed. Azole derivatives such as 2-mercaptobenzimidazole (2MBI, $\mathrm{C}_{7} \mathrm{H}_{6} \mathrm{~N}_{2} \mathrm{~S}$ ) are very often used as corrosion inhibitors for copper and have a remarkable efficiency under certain conditions [6-8].

2-MBI exists in two forms: the thione and the thiol forms. The former has $\mathrm{C}$ double bonded to $\mathrm{S}$, and the latter $\mathrm{C}$ double bonded to endocyclic $\mathrm{N}$ with hydrogen bonded to $\mathrm{S}$. The thione form is the preferred form of 2-MBI in solid and gaseous phase $[9,10]$. The bond lengths and angles of 2-MBI have been determined [10], and by considering the van der Waals radii of different atoms, its molecular dimensions can be deduced (see Fig. 1). 
Research has been carried out mostly on the metal/solution interface [11-18], indicating that the chemisorption of 2-MBI on copper surface forms a polymeric film which can protect it from corrosion. There are two nitrogen atoms and one sulfur atom in the 2-MBI molecule, which can concurrently or individually bond to the metal surface [12, 19]. Finšgar et al. $[16,17]$ confirmed that 2-MBI molecules are bonded to $\mathrm{Cu}$ through their $\mathrm{N}$ and $\mathrm{S}$ atoms on the oxidized copper surface, tilted relatively to the sample surface, as observed previously by Tooru $[20]$. Xue et al. $[12,14]$ reported that $2-\mathrm{MBI}$ is bonded to metallic copper through sulfur atom and the chemisorption is accompanied by a cleavage of the $\mathrm{C}=\mathrm{S}$ bond, not observed on oxidized copper surface. Hosseini et al. [21] investigated the adsorption of 2MBI on a less reactive metal surface, namely $\mathrm{Au}(111)$, and showed the formation of flat-lying molecules in the monolayer.

Molecular deposition by evaporation under ultra-high vacuum (UHV) can also be used as an approach to understand the molecule/surface interaction [22, 23]. Density functional theory studies suggest that 2-MBI neutral molecules in gaseous phase can chemisorb perpendicularly on the surface through $\mathrm{N}-\mathrm{Cu}$ or $\mathrm{S}-\mathrm{Cu}$ bond and physisorb almost parallel to the surface $[22,24]$, and that a monolayer of MBI adopting a $(\sqrt{7} \times \sqrt{7}) \mathrm{R} 19.1^{\circ}$ superstructure could form [25]. Despite these experimental and theoretical studies on copper corrosion inhibition by 2-MBI, the inhibition mechanism is not yet fully ascertained, neither the chemical nature of the resulting inhibitor films is completely established.

In this study, the adsorption of 2-MBI under ultra-low pressure (ULP) at room temperature on pristine and pre-oxidized $\mathrm{Cu}(111)$ surfaces by sublimation was investigated using Auger Electron Spectroscopy (AES), Scanning Tunneling Microscopy (STM), and X-ray Photoelectron Spectroscopy (XPS). The corrosion inhibition efficiency and thermal stability of the adsorbed molecular layers were examined.

Previously, we have investigated the adsorption of another structurally related inhibitor, 2-mercaptobenzothiazole (2-MBT), on $\mathrm{Cu}(111)$ surfaces using a similar approach [26, 27]. The molecule was found to adsorb flat with $\mathrm{S}$ bonded to $\mathrm{Cu}$, accompanied by a partial decomposition on metallic $\mathrm{Cu}(111)$. In this work, a comparative discussion will be included for better understanding of corrosion inhibition mechanisms, and to provide a rational basis 
for the design of new inhibitors.

\section{Experimental}

In this study, a high purity $(99.999 \%) \mathrm{Cu}(111)$ single-crystal was used. The surface was mechanically polished down to $0.25 \mu \mathrm{m}$ (diamond paste), and then electro-polished in $60 \mathrm{wt} \% \mathrm{H}_{3} \mathrm{PO}_{4}$ solution at $1.4 \mathrm{~V}$ during $5 \mathrm{~min}$, followed by annealing under $\mathrm{H}_{2}$ flow at $725^{\circ} \mathrm{C}$ during $20 \mathrm{~h}$ to reconstruct and recrystallize the surface. It was then introduced into the UHV system for further preparation by cycles of ion sputtering $\left(P_{\mathrm{Ar}}=1 \times 10^{-5}\right.$ mbar, $600 \mathrm{~V}, 20 \mathrm{~mA}, 30 \mathrm{~min})$ and annealing $\left(600^{\circ} \mathrm{C}, 30 \mathrm{~min}\right)$ in order to obtain a clean and well-structured surface. The base pressure of the UHV system is $10^{-10} \mathrm{mbar}$, and it is equipped with STM (Omicron, STM1 with SCALA system), AES (Omicron, model CMA100) and Low Energy Electron Diffraction (LEED, Omicron, spectaLEED). The surface was systematically checked by AES, LEED and STM until no contamination and a good surface organization were observed, characterized by a sharp $(1 \times 1)$ LEED pattern and a topography with large and flat terraces as verified by STM.

2-MBI molecule was purchased from Sigma-Aldrich. It is a white to beige powder with a purity higher than $98 \%$. The 2-MBI powder was placed in a vacuum sealed glass connected directly to a reactor attached to the UHV system. The pressure of 2-MBI in the reactor was $10^{-9}$ mbar at room temperature. The sample was kept at room temperature during the deposition process. Pre-oxidation of the copper surface was performed by introducing oxygen gas in the main chamber through a leak valve $\left(P_{\mathrm{O}_{2}}=5 \times 10^{-6}\right.$ mbar $)$ until saturation. In these conditions, a 2D surface oxide is formed [28-30]. The growth kinetics of 2-MBI on clean and pre-oxidized copper surfaces was followed by AES, and the surface structure changes were characterized by STM.

The STM measurements were performed at room temperature and in constant current mode. Image processing was carried out using WSxM software (5.0 Develop 9.1) [31]. No filtering was applied. All images were corrected by plane subtraction.

In order to determine the chemical composition of adsorbed molecular layers, the sample after 2-MBI deposition was transferred quickly to another UHV platform, equipped with 
XPS (Thermo Electron Corporation, ESCALAB 250) of base pressure of $10^{-10}$ mbar. A monochromatic $\mathrm{Al} \mathrm{K}_{\alpha}$ source $(1486.6 \mathrm{eV})$ was used and the binding energy was referenced by measuring the Fermi level position of the sample. The transmission of the analyzer was calibrated by measurement of reference samples. The survey spectra were recorded with a pass energy of $100 \mathrm{eV}$ corresponding to an overall resolution of $1.8 \mathrm{eV}$, the high resolution spectra were recorded with a pass energy of $20 \mathrm{eV}$ corresponding to an overall resolution of $360 \mathrm{meV}$. The take-off angle of the analyzed photoelectrons was $90^{\circ}$. The data processing was carried out using the CasaXPS software (version 2.3.19) [32].

\section{Results and discussion}

\subsection{2-MBI deposition on pristine $C u(111)$}

A pristine $\mathrm{Cu}(111)$ surface was prepared as described previously, 2-MBI exposure was then performed at ULP $\left(1 \times 10^{-9}\right.$ mbar $)$ at room temperature and the growth kinetics was followed by AES. The peak-to-peak height ratios of S $(151 \mathrm{eV}), \mathrm{C}(271 \mathrm{eV})$ and N (380 $\mathrm{eV})$ to $\mathrm{Cu}(920 \mathrm{eV})$ signals were recorded and corrected by the relative sensitivity $S_{x}$ of the Auger transitions. The normalized ratios are proportional to the atomic densities of each element, and plotted as a function of exposure to 2-MBI. The results are shown in Fig. 2.

We can see from the growth kinetics curves that the C, S and N signals increase firstly with increasing exposure, indicating the adsorption of 2-MBI on copper. A decrease of the adsorption rate is then observed, and finally a stationary regime is reached at an exposure of about $110 \mathrm{~L}$, indicating a copper surface saturated with 2-MBI.

In order to verify the stoichiometry of the molecule in the adsorbed layer, the atomic ratios of $\mathrm{S}$ and $\mathrm{N}$ to $\mathrm{C}$ were calculated, and were compared to the theoretical (molecule stoichiometry) values. At early stage of growth, the $\mathrm{N}$ to $\mathrm{C}$ atomic ratio increases rapidly with increasing exposure, and stabilize at the theoretical value $(2 / 7)$ within the error bars after about $11 \mathrm{~L}$. At the same time, a fast decrease of the $\mathrm{S}$ to $\mathrm{C}$ atomic ratio was observed, followed by a slight increase to stabilize at about 1.5 times the theoretical value $(1 / 7)$. This seems to indicate that there is a transition in the growth mode of $2-\mathrm{MBI}$ at about $11 \mathrm{~L}$, 


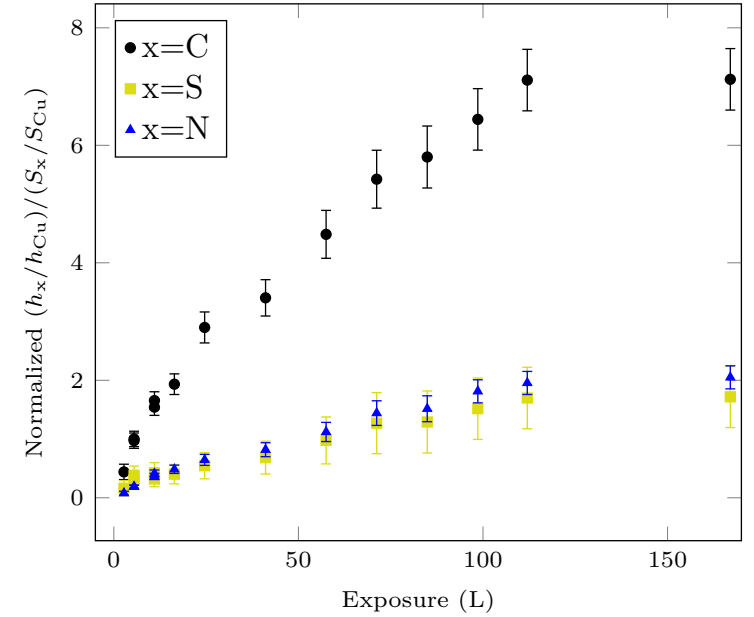

(a)

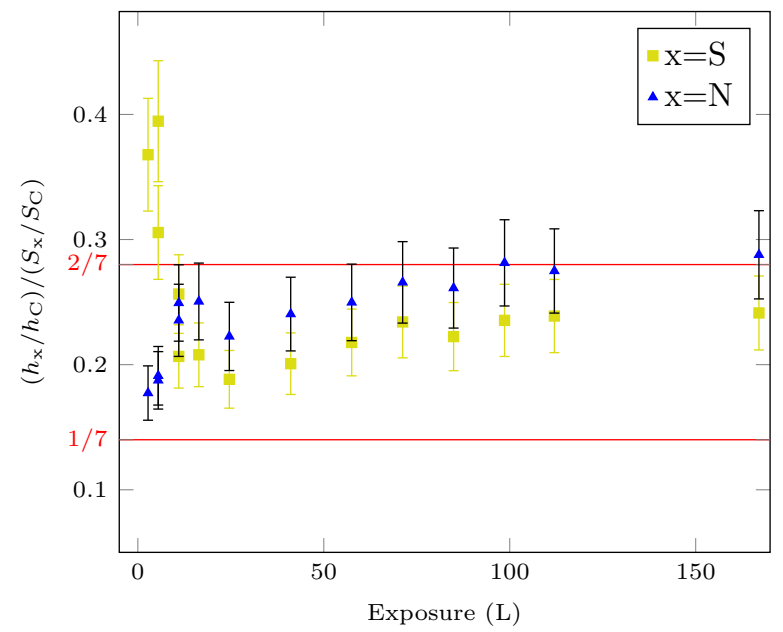

(b)

Figure 2: Growth kinetics of 2-MBI on pristine $\mathrm{Cu}(111)$ at room temperature: (a) change in the normalized AES peak-to-peak height ratios as a function of 2-MBI exposure at $1 \times 10^{-9}$ mbar and RT; (b) evolution of $\mathrm{S}$ and $\mathrm{N}$ to $\mathrm{C}$ atomic ratios with 2-MBI exposure.

and the excess of S suggests that the molecule may partially decompose when adsorbed on metallic $\mathrm{Cu}(111)$. Similar results were observed on 2-MBT, with a saturation regime reached at about $100 \mathrm{~L}$ and an excess of S attributed to the decomposition of 2-MBT [27].

The surface topography after different exposures was characterized by STM. After an exposure of $5 \mathrm{~L}$, STM images show the formation of self-assembled monolayer on $\mathrm{Cu}(111)$, as can be seen in Fig. 3. The surface remains flat and homogeneous. Different structures coexist on the sample surface, and the lattice unit cell is marked by the black rhombus. A $(\sqrt{7} \times \sqrt{7})$ R19.1 ${ }^{\circ}$ structure is formed as shown in Fig. 3a. This is the characteristic structure formed by atomic $\mathrm{S}$ on $\mathrm{Cu}(111)$ surface at saturation [33, 34], suggesting the adsorption of atomic $\mathrm{S}$ resulting from molecular decomposition. This could explain the excess of $\mathrm{S}$ observed by AES. A long-range hexagonal structure with lattice parameter of $2.0 \pm 0.2 \mathrm{~nm}$ is observed, as shown in Fig. 3b, and is assigned to a $(8 \times 8)$ structure. Images of different aspects are observed at different applied potentials, and only one is chosen to be presented. The size of one pattern is $1.5 \pm 0.3 \mathrm{~nm}$, which is $2-3$ times the size of one 2-MBI molecule. Thus the $(8 \times 8)$ structure may correspond to the adsorption of 2-MBI clusters. Moreover, a structure 


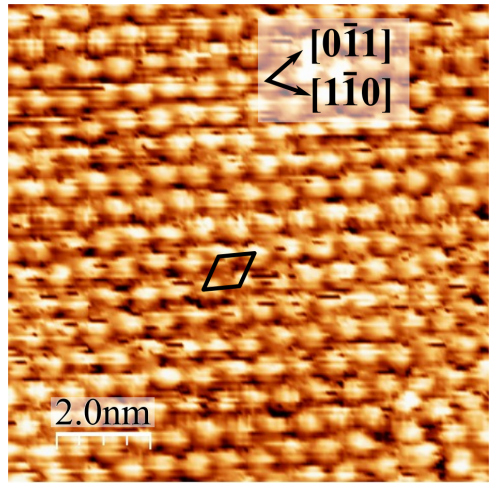

(a)

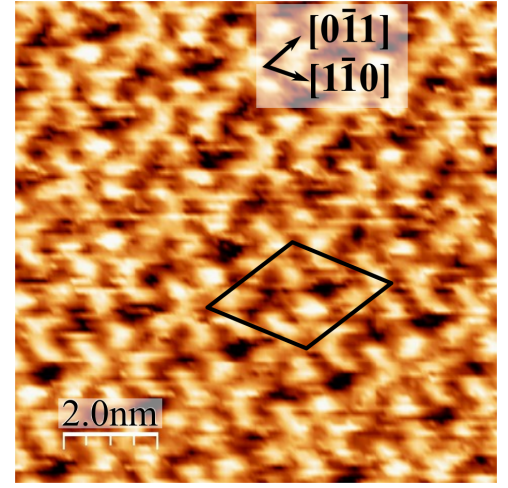

(b)

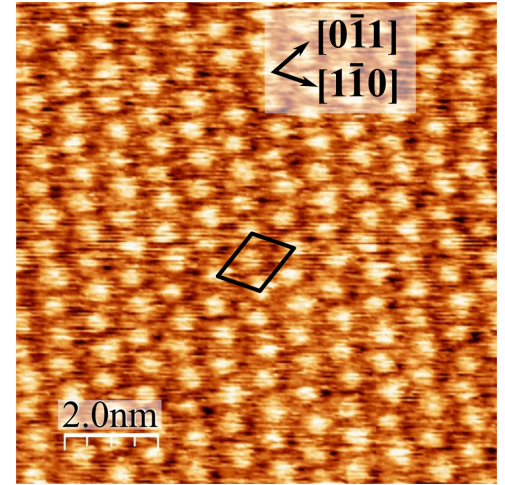

(c)

Figure 3: Drift-corrected STM images for $5 \mathrm{~L}$ of 2-MBI on $\mathrm{Cu}(111)$ obtained at different locations on the surface: (a) $(\sqrt{7} \times \sqrt{7}) \mathrm{R} 19.1^{\circ}$ structure $(10 \mathrm{~nm} \times 10 \mathrm{~nm}, V=-1.5 \mathrm{~V}, I=2.0 \mathrm{nA})$; (b) $(8 \times 8)$ structure $(10$ $\mathrm{nm} \times 10 \mathrm{~nm}, V=-1.5 \mathrm{~V}, I=2.0 \mathrm{nA}$ ); (c) $10 \mathrm{~nm} \times 10 \mathrm{~nm}, V=2.0 \mathrm{~V}, I=1.5 \mathrm{nA}$. Main directions of the $\mathrm{Cu}$ surface are indicated as well as the superstructure unit cell formed by the adsorbate.

with lattice constant of $(8.6 \pm 0.2) \AA \times(10.7 \pm 0.1) \AA$ is also observed (Fig. 3c). This structure with intermediate lattice parameter may serve as a transition between the two previous structures.

Further exposure of the sample to 2-MBI up to $11 \mathrm{~L}$ leads to the formation of a second molecular layer, as can be seen in Fig. 4. This is in good agreement with AES measurements (Fig. 2) showing a change of slope at $11 \mathrm{~L}$. The surface is always flat with large terraces, and the second layer is incomplete, with domains delimited by dark lines following three preferential directions, as indicated in Fig. 4b. The two directions marked '1' and '2' are orientated along the principal direction of the $(8 \times 8)$ structure formed on the first monolayer underneath, and the direction ' 3 ' is closer to the principal direction of the $(\sqrt{7} \times \sqrt{7}) \mathrm{R} 19.1^{\circ}$ structure. Moreover, local order can be observed but no obvious long range ordering was evidenced by Fast Fourier Transform (FFT) of the second layer.

Fig. $4 \mathrm{c}$ is a zoom in on a different region in the second layer, and we can see the selfassembled monolayer underneath. No ordered structure is observed by FFT. The apparent height difference between the first and second layer is measured by a profile, giving a thickness of about 1.2 $\AA$. Taking into account the dimension of the molecule, 2-MBI lies flat in the second layer with its plane almost parallel to the sample surface. 


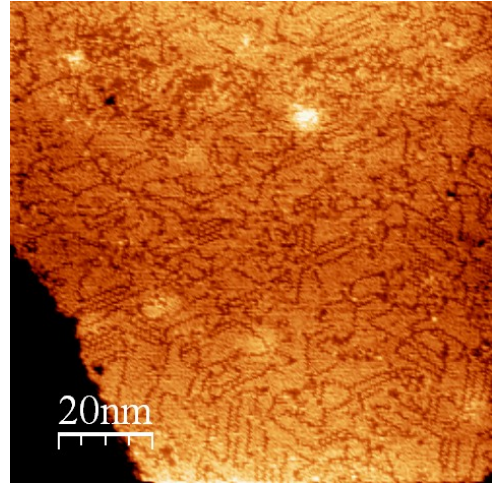

(a)

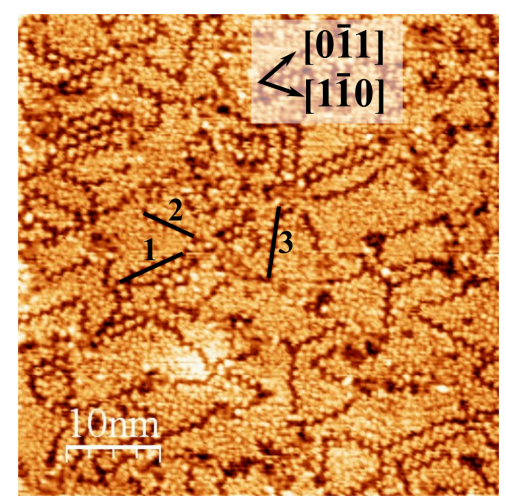

(b)

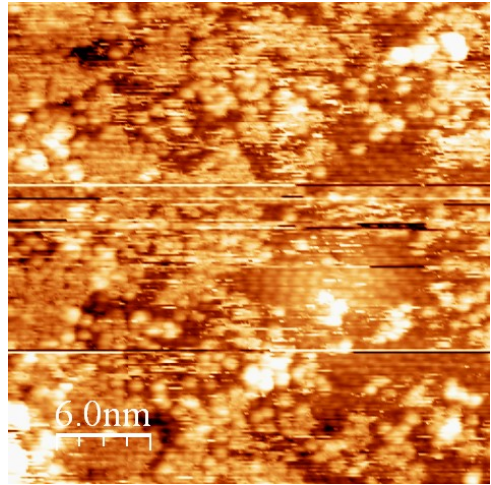

(c)

Figure 4: $\mathrm{STM}$ images for $11 \mathrm{~L}$ of 2-MBI on $\mathrm{Cu}(111)$ : (a) $100 \mathrm{~nm} \times 100 \mathrm{~nm}, V=-1.5 \mathrm{~V}, I=0.5 \mathrm{nA}$; (b) $50 \mathrm{~nm} \times 50 \mathrm{~nm}, V=-1.5 \mathrm{~V}, I=0.5 \mathrm{nA}$; (c) $30 \mathrm{~nm} \times 30 \mathrm{~nm}, V=-1.0 \mathrm{~V}, I=1.0 \mathrm{nA}$.

At higher exposure, multilayers of 2-MBI were formed on $\mathrm{Cu}(111)$. FFT did not reveal any ordered local structure. The surface becomes rougher but we can still see different terraces. The outermost molecular layer is always incomplete, as shown in Fig. 5a and Fig. 5b. This contrast corresponds to the difference in height, i.e. the thickness of the outermost molecular layer. The height distribution of Fig. 5b was plotted with a bin size of $35 \mathrm{pm}$, as shown in Fig. 5c, and gives a layer thickness of $1.7 \AA$ as well as a surface covered fraction of $86 \pm 1 \%$ by the incomplete outermost layer. Taking into account the molecular dimensions of 2-MBI, this indicates that the 2-MBI in the outermost molecular layer adsorbs with its plane almost parallel to the sample surface.

Once the surface topography at different exposures was determined by STM, XPS analyzes were then performed on monolayer $(5 \mathrm{~L})$ and multilayer $(167 \mathrm{~L})$ of 2 -MBI in order to characterize their chemical composition, and the results are shown in Fig. 6. The S $2 \mathrm{p}$ spectra were decomposed using spin-orbit doublets $\mathrm{S} 2 \mathrm{p}_{1 / 2}$ and $\mathrm{S} 2 \mathrm{p}_{3 / 2}$, with a branching ratio of 0.5 and spin-orbit splitting of $1.18 \mathrm{eV}[35,36]$. The $\mathrm{S} 2 \mathrm{p}$ spectrum of the 2-MBI monolayer is composed of a $\mathrm{S}_{2}$ component, with the $2 \mathrm{p}_{3 / 2}$ at $161.8 \mathrm{eV}$. This component is slightly shifted to higher binding energy $(0.4 \mathrm{eV})$ compared to that observed for a 2-MBT monolayer adsorbed on $\mathrm{Cu}(111)$ [26]. This may be explained by the surface oxidation during transfer to XPS which modifies the chemical environment of 2-MBI in the adsorbed mono- 


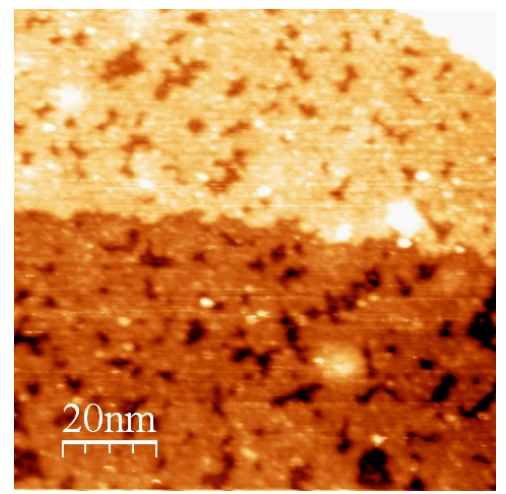

(a)

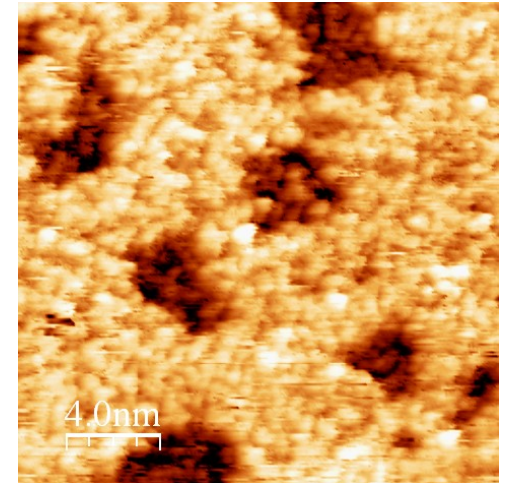

(b)

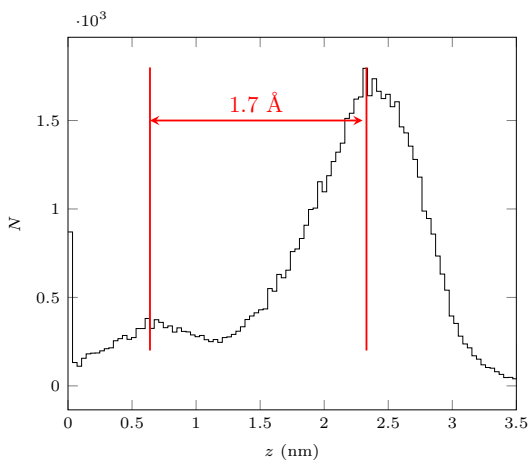

(c)

Figure 5: STM images for 2-MBI exposure on $\mathrm{Cu}(111)$ : (a) $41 \mathrm{~L}(100 \mathrm{~nm} \times 100 \mathrm{~nm}, V=1.5 \mathrm{~V}, I=0.5$ nA); (b) $57 \mathrm{~L}(20 \mathrm{~nm} \times 20 \mathrm{~nm}, V=-1.8 \mathrm{~V}, I=0.3 \mathrm{nA}) ;(\mathrm{c})$ Height histogram of image (b).
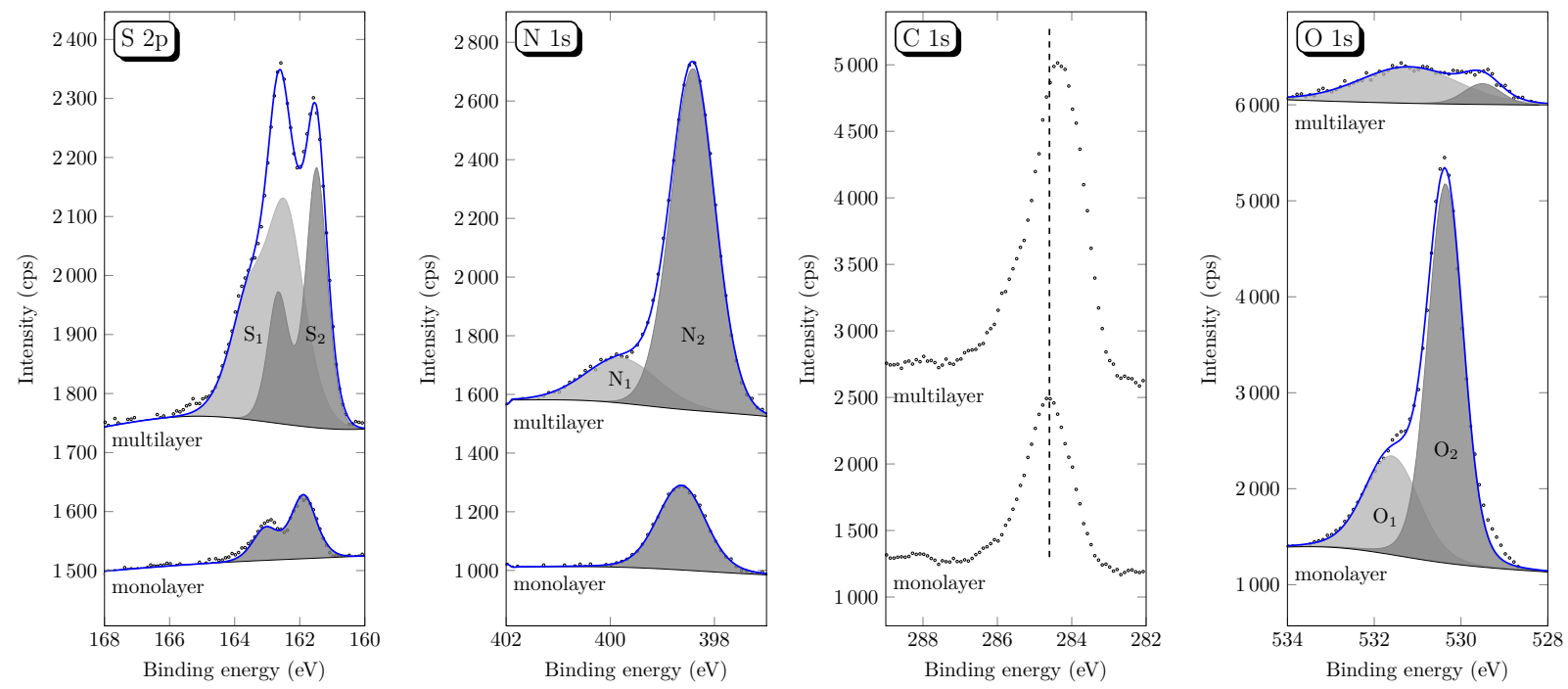

Figure 6: XPS spectra of the S 2p, N 1s, C 1s and O 1s core levels after 2-MBI exposure on metallic Cu(111) surface at $1 \times 10^{-9}$ mbar and RT. 
layer. Taking into account the AES and STM observations, $\mathrm{S}_{2}$ is assigned to $\mathrm{S}$ bonded to metallic $\mathrm{Cu}$, both in the atomic form and in the intact molecule, as also observed for 2-MBT [26]. As for 2-MBI multilayer, the $\mathrm{S}_{2}$ component at $161.5 \mathrm{eV}$ is also observed, with higher intensity compared to that obtained on $\mathrm{Cu}(111)$ with a 2-MBI monolayer, suggesting that the molecules are also bonded to copper in the multilayer, probably due to a reconstruction of the copper substrate. Moreover, another component $\mathrm{S}_{1}$ is observed at binding energy of $162.4 \mathrm{eV}$ for $2 \mathrm{p}_{3 / 2}$. This agrees with the position of $2-\mathrm{MBI}$ reported previously [16, 20] and with that of the exocyclic $\mathrm{S}$ in 2-MBT [26]. $\mathrm{S}_{1}$ is thus assigned to $\mathrm{S}$ in the 2-MBI molecule non bonded to $\mathrm{Cu}$ in the multilayer.

Analysis of the $\mathrm{N}$ 1s spectra gives a component $\mathrm{N}_{2}$ at $398.6 \mathrm{eV}$ in the monolayer of 2MBI, with full widths at half maximum (FWHM) of $1.0 \mathrm{eV}$. The intensity of this component increases in the multilayer, with appearance of another component $\mathrm{N}_{1}$ at $399.8 \mathrm{eV}$ with larger FWHM. However, the N 1s peak for the 2-MBI crystalline powder presents only one component at $400.5 \mathrm{eV}[16,20]$. It is difficult to determine the nature of $\mathrm{N}_{1}$ component, but the shift to lower binding energy of $\mathrm{N}_{2}$ component $(1.9 \mathrm{eV})$ observed in the monolayer and multilayer of 2-MBI suggests that $\mathrm{N}$ atoms are involved in the surface interaction with copper, acting as electron acceptor. Similar phenomenon has been observed for 2-MBI interaction with copper in solution [16].

Moreover, because of non-obvious peak separation and the interaction of the molecule with copper leading to a partial decomposition of 2-MBI, as well as the influence of transfer to air, the decomposition of $\mathrm{C} 1 \mathrm{~s}$ region does not give reliable information and is thus not performed. The small peak at binding energy of about $288 \mathrm{eV}$ is assigned to carboxylic groups (air contamination). The O 1s spectrum of the 2-MBI monolayer shows two components $\mathrm{O}_{1}$ and $\mathrm{O}_{2}$, at binding energies of $531.6 \mathrm{eV}$ and $530.4 \mathrm{eV}$, respectively. $\mathrm{O}_{2}$ component is usually attributed to a bulk oxide ligands, and $\mathrm{O}_{1}$ may be assigned to the $\mathrm{OH}$ groups resulting from dissociative adsorption of water and/or oxygenated contaminations [37, 38]. The intensity of the $\mathrm{O}$ 1s spectrum decreases to $1 / 4$ with 2-MBI multilayer, indicating a better protection of copper compared to the monolayer. The stronger oxidation of copper with 2-MBI monolayer results in an enhanced attenuation of the molecular layer, thus a 


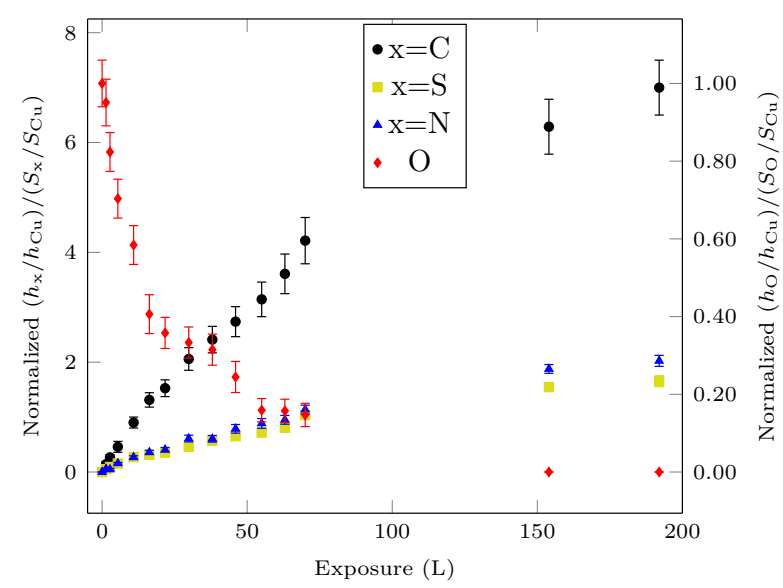

(a)

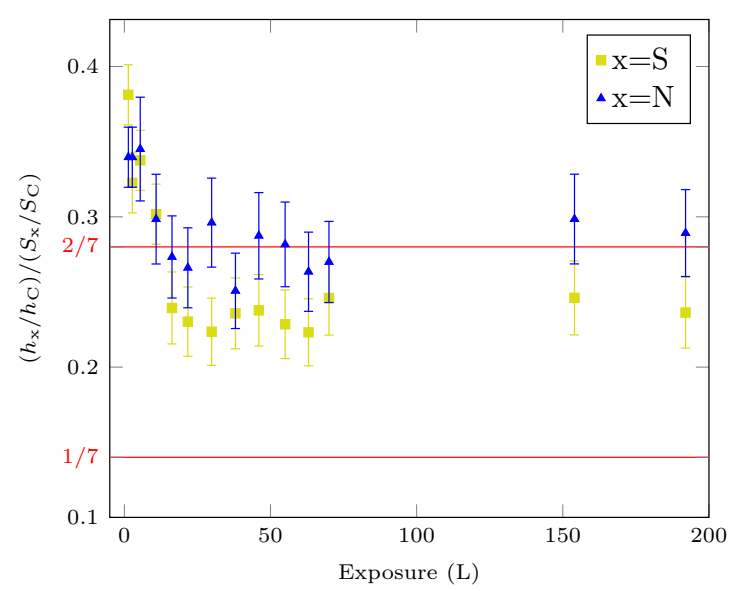

(b)

Figure 7: Growth kinetics of 2-MBI on pre-oxidized $\mathrm{Cu}(111)$ at room temperature: (a) change in the normalized AES peak-to-peak height ratios as a function of 2-MBI exposure at $1 \times 10^{-9}$ mbar and RT; (b) evolution of $\mathrm{S}$ and $\mathrm{N}$ to $\mathrm{C}$ atomic ratios with 2-MBI exposure.

decrease in the intensity of the S $2 \mathrm{p}$ and $\mathrm{N}$ 1s spectra.

By assuming a homogeneous and continuous layer of 2-MBI and by applying the same method as in Ref. [26], we estimate an equivalent thickness of the 2-MBI multilayer to be $1.0 \pm 0.2 \mathrm{~nm}$, corresponding to $7 \pm 2$ layers of 2-MBI given the thickness of one layer of $1.5 \pm 0.3 \AA$ measured previously by STM. This is almost 2 times that formed by 2-MBT. Note that the presence of oxygen in the 2-MBI multilayer is neglected for the calculation.

\subsection{2-MBI deposition on pre-oxidized Cu(111)}

In order to investigate the influence of oxygen on the adsorption of 2-MBI, a pre-oxidized $\mathrm{Cu}(111)$ surface was prepared as described above, then the surface was exposed to 2-MBI at ULP $\left(1 \times 10^{-9} \mathrm{mbar}\right)$. The growth kinetics of 2-MBI on pre-oxidized $\mathrm{Cu}(111)$ surface was followed by AES. Fig. 7 shows the change in the peak-to-peak height ratios of $\mathrm{S}(151 \mathrm{eV})$, $\mathrm{C}(271 \mathrm{eV})$ and $\mathrm{N}(380 \mathrm{eV})$ to $\mathrm{Cu}(920 \mathrm{eV})$ signals as a function of exposure to 2-MBI.

Firstly, we can see that the $\mathrm{S}, \mathrm{C}$ and $\mathrm{N}$ signals increase with increasing exposure, indicating the growth of 2-MBI layer on the pre-oxidized copper surface. Then a saturation regime is reached, characterized by the plateau in the $\mathrm{S}, \mathrm{C}$ and $\mathrm{N}$ signals. The surface is saturated with 2-MBI after an exposure of about 190 L. No significant change is observed compared 
to the growth kinetics of 2-MBI on metallic $\mathrm{Cu}(111)$. However, compared to the adsorption of 2-MBT which reaches its saturation regime at about $50 \mathrm{~L}$ on pre-oxidized $\mathrm{Cu}(111)[27]$, a much slower growth kinetics is evidenced for 2-MBI.

Meanwhile, the normalized $\left(h_{\mathrm{O}} / h_{\mathrm{Cu}}\right) /\left(S_{\mathrm{O}} / S_{\mathrm{Cu}}\right)$ signal decreases continuously with increasing exposure until a total disappearance of oxygen at an exposure of about $150 \mathrm{~L}$, indicating the substitution of oxygen by 2-MBI at room temperature taking into account the inelastic mean free path of oxygen and copper Auger electrons. The same phenomenon has been observed for 2-MBT and $\mathrm{H}_{2} \mathrm{~S}$ exposure on pre-oxidized $\mathrm{Cu}(111)[27,39]$. However, in the case of 2-MBT, oxygen desorbs completely at about $25 \mathrm{~L}$. This indicates that 2-MBT is more reactive on pre-oxidized copper surface.

Similarly, the atomic ratios of $\mathrm{S}$ and $\mathrm{N}$ to $\mathrm{C}$ in the adsorbed layer were calculated, and were compared to the theoretical (molecule stoichiometry) values. The $\mathrm{S}$ and $\mathrm{N}$ to $\mathrm{C}$ ratios decrease firstly and reach a stationary regime at about $16 \mathrm{~L}$, with a $\mathrm{N}$ to $\mathrm{C}$ ratio close to the theoretical value $(2 / 7)$, confirming the adsorption of $2-\mathrm{MBI}$, and a $\mathrm{S}$ to $\mathrm{C}$ ratio about 1.5 times the theoretical value (1/7), suggesting a partial decomposition of 2-MBI. Compared to the deposition on metallic $\mathrm{Cu}(111)$, the high values of $\mathrm{N}$ to $\mathrm{C}$ ratio in the early stage of growth may be assigned to geometric effects due to the difference in the film structure, i.e. the relative orientation of the molecule compared to the sample surface.

The surface topography before and after molecule deposition was characterized by STM, as shown in Fig. 8. The STM image of the pre-oxidized surface (Fig. 8a) confirms the formation of a flat bi-dimensional copper oxide covering the atomically flat substrate terraces, accompanied by a reconstruction of the step edges. The oxide takes the form of the '29' superstructure. After 2-MBI deposition (Fig. 8b), no remarkable change of the surface morphology is observed. The step edges becomes straight, but the terraces remain flat and homogeneous. The influence of noise on the image can be observed but no ordered local structure is evidenced, even when zoom in on one terrace. Moreover, compared to the adsorption of 2-MBI on metallic $\mathrm{Cu}(111)$ which leads to the formation of an incomplete outermost molecular film, pre-oxidation of copper prior to exposure effectively change the morphology of the adsorbed 2-MBI layer by forming a complete molecular film. 


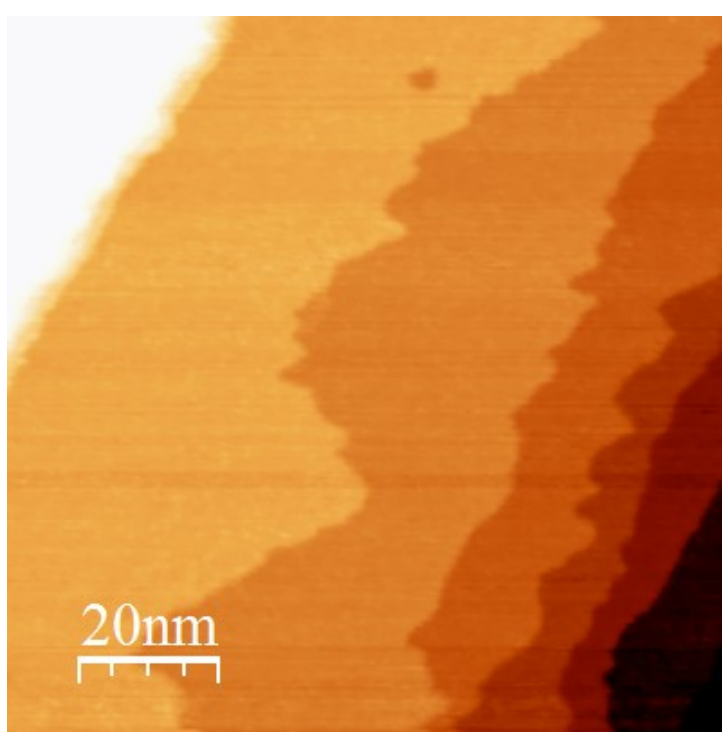

(a)

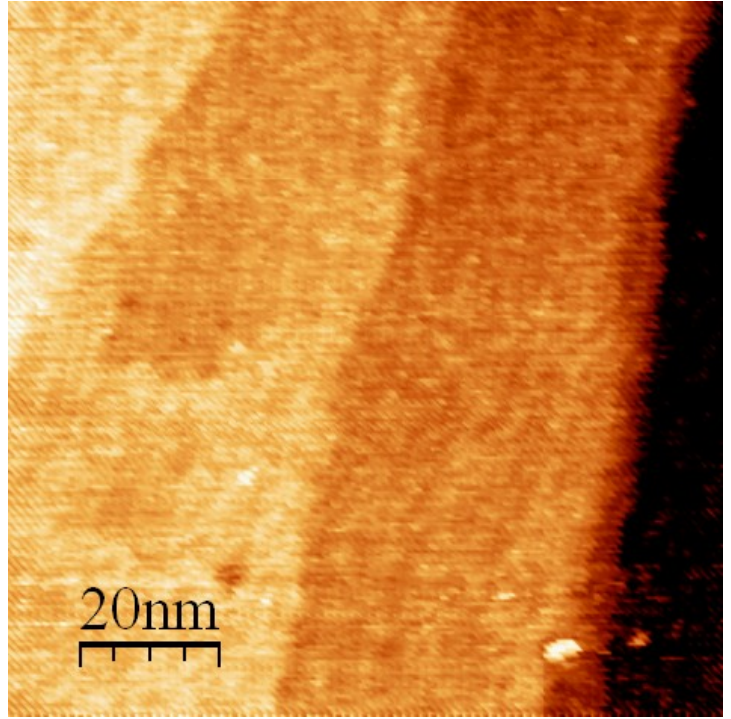

(b)

Figure 8: STM images of pre-oxidized $\mathrm{Cu}(111)$ surface: (a) before exposure to 2-MBI $(100 \mathrm{~nm} \times 100 \mathrm{~nm}$, $V=1.0 \mathrm{~V}, I=0.2 \mathrm{nA})$; (b) after $11 \mathrm{~L}$ of 2 -MBI $(100 \mathrm{~nm} \times 100 \mathrm{~nm}, V=1.0 \mathrm{~V}, I=0.3 \mathrm{nA})$.

The chemical composition of multilayer (191 L) of 2-MBI adsorbed on pre-oxidized $\mathrm{Cu}(111)$ was characterized by XPS, and is shown in Fig. 9. The $\mathrm{S} 2 \mathrm{p}$ spectrum shows the presence of two components $\mathrm{S}_{1}$ and $\mathrm{S}_{2}$, with the $2 \mathrm{p}_{3 / 2}$ at $162.5 \mathrm{eV}$ and $161.5 \mathrm{eV}$, corresponding to $\mathrm{S}$ in the non bonded molecule and $\mathrm{S}$ bonded to $\mathrm{Cu}$, respectively. Compared to the 2-MBI multilayer adsorbed on metallic $\mathrm{Cu}(111)$, the total intensity of $\mathrm{S} 2 \mathrm{p}$ spectrum decreases to half, mainly associated to the decrease of the $\mathrm{S}_{2}$ component, accompanied by a decrease in the FWHMs of $\mathrm{S}_{1}$ and $\mathrm{S}_{2}$ components, indicating a difference in the structure of the adsorbed layer. This decrease in the intensity of $\mathrm{S}$ bonded to $\mathrm{Cu}$ may be explained by a reduced decomposition of the molecule. The $\mathrm{N} 1$ s spectrum shows a component $\mathrm{N}_{2}$ at $398.4 \mathrm{eV}$ as for adsorption on metallic $\mathrm{Cu}(111)$, indicating an interaction of $\mathrm{N}$ with $\mathrm{Cu}$. As previously, the decomposition of $\mathrm{C} 1 \mathrm{~s}$ spectrum is not performed, but a slight shift of $0.2 \mathrm{eV}$ to lower binding energy is observed. The intensity of the $\mathrm{O}$ 1s spectrum is 1.6 times that obtained on metallic $\mathrm{Cu}(111)$ with $2-\mathrm{MBI}$ multilayer, but remains low compared to that with 2-MBI monolayer. Similarly, the equivalent thickness of the 2-MBI multilayer was estimated to be $0.6 \pm 0.1 \mathrm{~nm}$, which is thinner than that formed on metallic $\mathrm{Cu}(111)$. This decrease in 

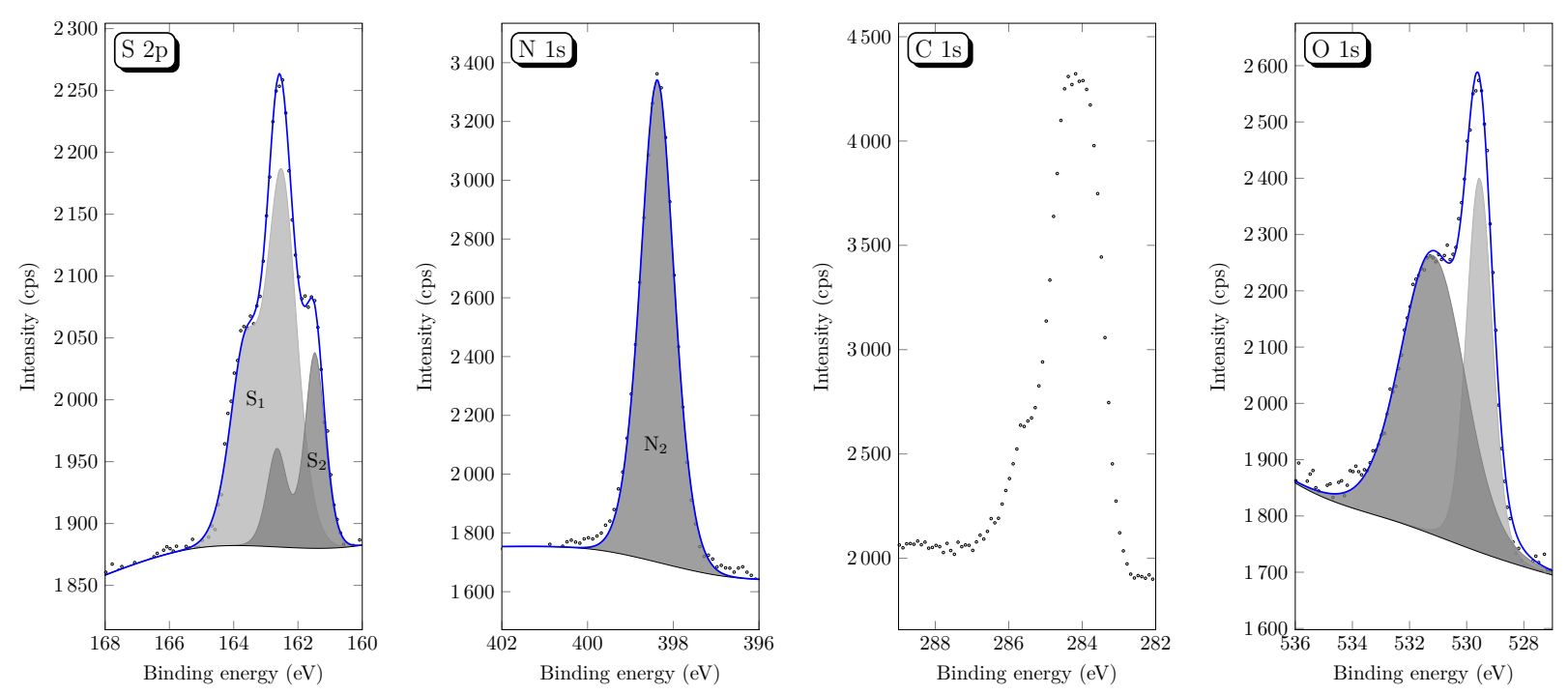

Figure 9: XPS spectra of the S 2p, N 1s, C 1s and O 1s core levels after $191 \mathrm{~L}$ 2-MBI exposure on pre-oxidized $\mathrm{Cu}(111)$ surface at $1 \times 10^{-9} \mathrm{mbar}$ and $\mathrm{RT}$.

layer thickness contributes to a decrease in the attenuation of the layer underneath, which confirms a lower concentration of S bonded to copper on pre-oxidized surface.

\subsection{Thermal stability of 2-MBI multilayer}

The stability of the 2-MBI multilayer adsorbed on metallic $\mathrm{Cu}(111)$ was investigated by annealing at different temperatures, and the surface was characterized by AES and STM. After annealing at $200^{\circ} \mathrm{C}$ (Fig. 10a), reorganization of the sample surface is observed. The step edges are realigned, and the molecular layer becomes flat and homogeneous. The outermost molecular layer is more compact.

Further annealing results in the formation of an overall $(\sqrt{7} \times \sqrt{7}) \mathrm{R} 19.1^{\circ}$ structure at temperature above $500^{\circ} \mathrm{C}$ (Fig. 10b), corresponding to the adsorption of atomic $\mathrm{S}$ on copper. This indicates a dissociation of 2-MBI after annealing above $500^{\circ} \mathrm{C}$, and the adsorption of atomic $\mathrm{S}$ on $\mathrm{Cu}(111)$. No change is evidenced by AES until $500^{\circ} \mathrm{C}$. Compared to 2-MBT multilayer which decomposes at $100^{\circ} \mathrm{C}$ [27], a higher stability is evidenced for 2-MBI. This is consistent with a higher adsorption energy of 2-MBI obtained by DFT calculation [25]. 


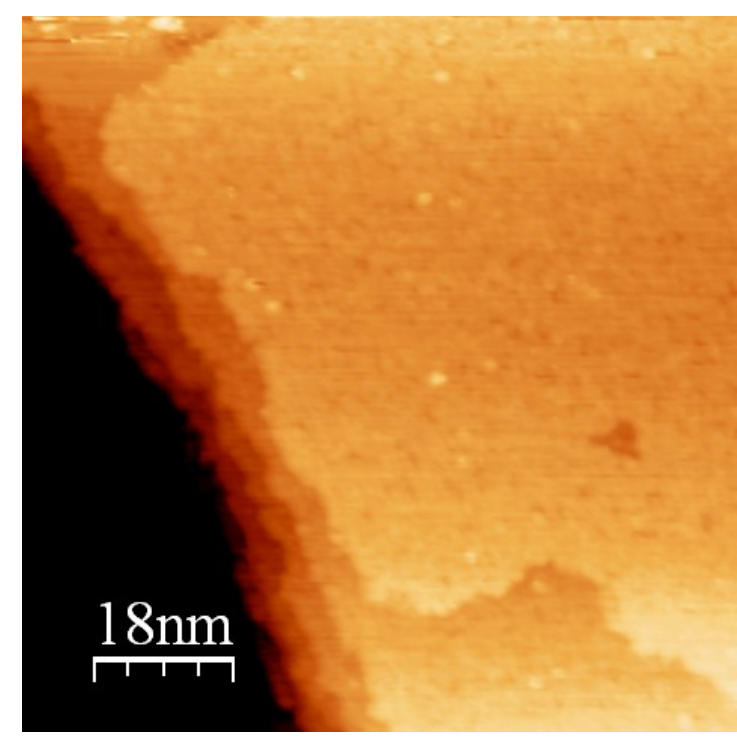

(a)

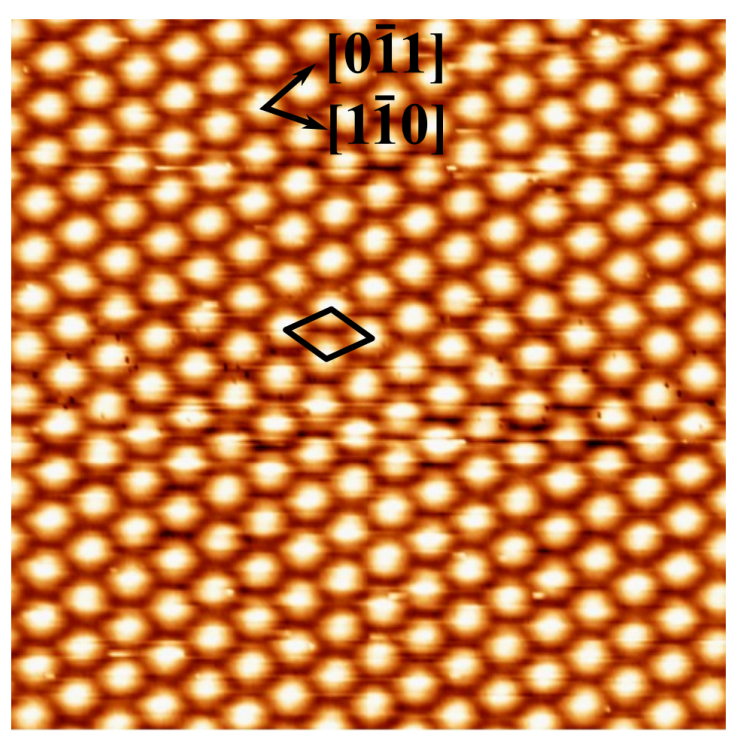

(b)

Figure 10: STM images of 2-MBI multilayer on metallic $\mathrm{Cu}(111)$ surface (a) after annealing at $200^{\circ} \mathrm{C}(90$ $\mathrm{nm} \times 90 \mathrm{~nm}, V=0.5 \mathrm{~V}, I=0.5 \mathrm{nA})$; (b) after annealing at $500^{\circ} \mathrm{C}(10 \mathrm{~nm} \times 10 \mathrm{~nm}, V=0.8 \mathrm{~V}, I=0.3$ $\mathrm{nA})$, main directions of the $\mathrm{Cu}$ surface and the $(\sqrt{7} \times \sqrt{7}) \mathrm{R} 19.1^{\circ}$ superstructure unit cell are indicated.

\subsection{Oxidation inhibition by 2-MBI adsorbed on $C u(111)$}

In order to test the inhibition efficiency of 2-MBI, the oxidation kinetics of $\mathrm{Cu}(111)$ with pre-adsorbed 2-MBI monolayer $(5 \mathrm{~L})$ and multilayer $(167 \mathrm{~L})$ were recorded at $P_{\mathrm{O}_{2}}=5 \times 10^{-6}$ mbar at room temperature by AES, and the results are shown in Fig. 11.

In the presence of a pre-adsorbed 2-MBI monolayer, a slight increase in the oxygen intensity is observed, much slower compared to the oxidation kinetics of metallic $\mathrm{Cu}(111)$ $[26,29]$. Since the value of $h_{\mathrm{O}} / h_{\mathrm{Cu}}$ is $\sim 0.22$ for the $2 \mathrm{D}$ oxide layer formed on $\mathrm{Cu}(111)$ at saturation, the oxide coverage on $\mathrm{Cu}(111)$ with pre-adsorbed 2-MBI monolayer at an oxygen exposure of $10^{4} \mathrm{~L}$ is about $20 \%$. This small oxidation may be explained by the presence of local defects in the 2-MBI monolayer. However, with pre-adsorbed 2-MBI multilayer, no oxygen uptake is observed. The comparison between the oxidation kinetics with and without pre-adsorbed 2-MBI indicates that a multilayer of 2-MBI can effectively protect the copper surface from oxygen adsorption in these conditions of temperature and pressure, and thus prevent the the initial stages of oxidation of copper. The molecule may prevent 


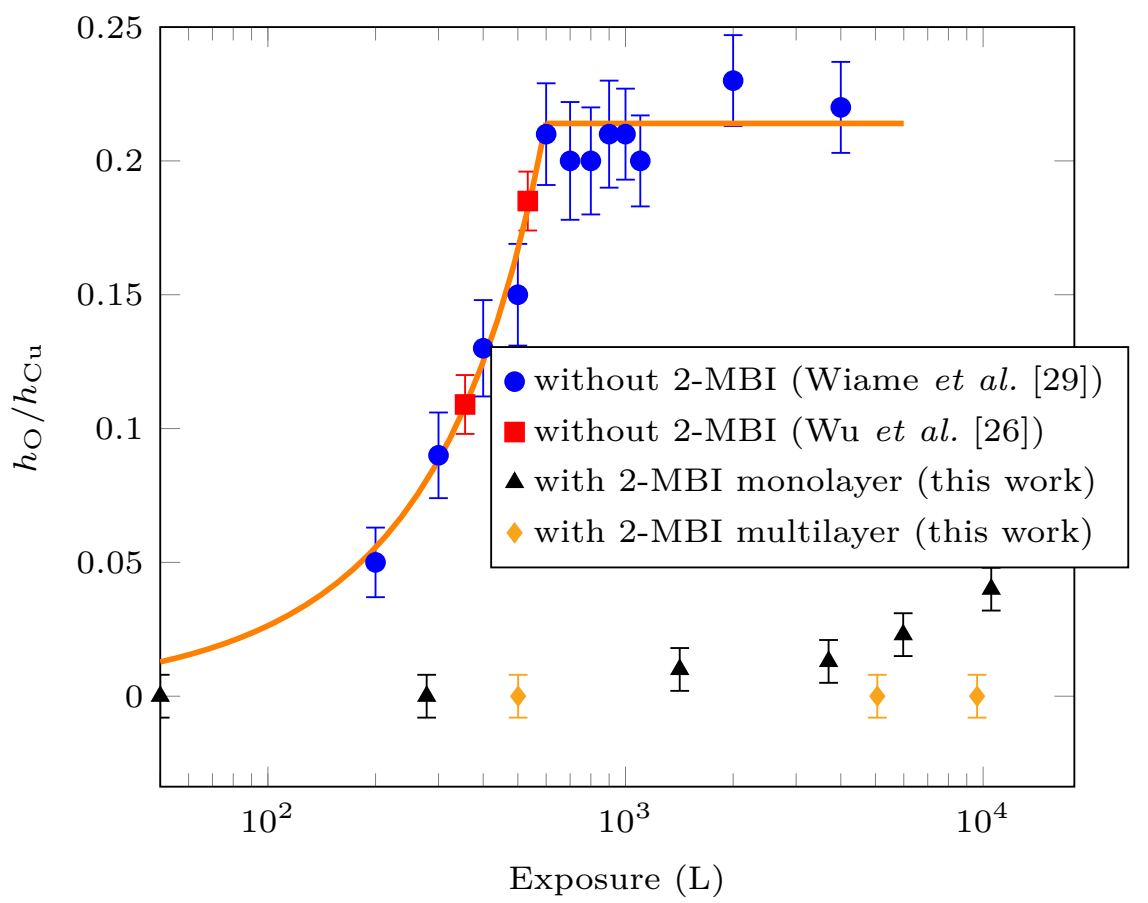

Figure 11: Oxidation kinetics of $\mathrm{Cu}(111)$ : effect of adsorbed 2-MBI monolayer (5 L) and multilayer (167 L) at RT prior to oxidation.

the dissociation of oxygen by blocking the oxygen adsorption sites. In the case of 2-MBT, the oxygen adsorption was blocked by a 2-MBT monolayer, with defective sites representing only about $8 \%$ of the surface area [26]. Thus 2-MBT monolayer offers a better protection against the initial stages of oxidation compared to 2-MBI.

\section{Conclusions}

This study reports the investigation of corrosion inhibition of 2-MBI on $\mathrm{Cu}$ at the molecular scale. Growth of molecular films on pristine and pre-oxidized $\mathrm{Cu}(111)$ surfaces at $1 \times 10^{-9}$ mbar and room temperature was evidenced by AES, with an excess of S, suggesting a partial decomposition of 2-MBI.

On clean, metallic $\mathrm{Cu}(111)$ surface, STM images reveal the formation of a self-assembled monolayer at $5 \mathrm{~L}$, with the coexistence of different structures including a $(\sqrt{7} \times \sqrt{7}) \mathrm{R} 19.1^{\circ}$ structure due to the adsorption of atomic S, and a $(8 \times 8)$ structure which may be assigned 
to the adsorption of 2-MBI clusters. An incomplete second layer is formed at $11 \mathrm{~L}$ with a thickness of $1.2 \AA$, further exposure results in multilayer adsorption with incomplete topmost molecular layer of thickness of $1.7 \AA$, indicating flat-lying molecules on the sample surface. XPS analysis indicates that $\mathrm{S}$ and $\mathrm{N}$ both interact with copper, as confirmed by the presence of a S $2 \mathrm{p}_{3 / 2}$ peak at $161.7 \pm 0.2 \mathrm{eV}$ and a $\mathrm{N} 1$ s peak at $398.5 \pm 0.1 \mathrm{eV}$.

2-MBI exposure on pre-oxidized $\mathrm{Cu}(111)$ leads to the formation of a flat, homogeneous and complete molecular layer through bonding of S and $\mathrm{N}$ to copper. No ordered structure is observed by STM. A substitution of oxygen in the 2D oxide layer is evidenced by AES.

A surface reorganization of the molecular layer adsorbed on metallic $\mathrm{Cu}(111)$ is observed at $200^{\circ} \mathrm{C}$, followed by the appearance of $(\sqrt{7} \times \sqrt{7}) \mathrm{R} 19.1^{\circ}$ structure on the whole surface, indicating the decomposition of $2-\mathrm{MBI}$ at $500^{\circ} \mathrm{C}$. Moreover, $\mathrm{Cu}(111)$ oxidizes much slower with a pre-adsorbed 2-MBI monolayer, while the presence of a multilayer of 2-MBI prevents the initial stages of oxidation of $\mathrm{Cu}(111)$ at low $\mathrm{O}_{2}$ pressure and room temperature.

Finally, the comparison with 2-MBT indicates that the molecular layer formed by 2-MBI on pristine $\mathrm{Cu}(111)$ is more stable, but is less effective on corrosion protection due to the presence of local defects. Furthermore, 2-MBI interacts much more slowly with pre-oxidized $\mathrm{Cu}(111)$ surface. Thus 2-MBT may offer a better corrosion inhibition for copper at room temperature.

\section{Acknowledgments}

This project has received funding from the European Research Council (ERC) under the European Union's Horizon 2020 research and innovation program (ERC Advanced Grant CIMNAS no. 741123).

\section{References}

[1] Procter, Gamble, Ltd. British Patent 652339 (1947).

[2] J. Bregman, Corrosion Inhibitors, Collier MacMillan Co., London, 1963.

[3] C. Nathan, Corrosion Inhibitors, National Association of Corrosion Engineers (NACE), Houston, Texas, 1973. 
[4] N. Putilova, S. Balezin, V. Barannik, Metallic Corrosion Inhibitors, Pergamon Press, London, 1966.

[5] M. Ranney, Inhibitors-Manufacture and Technology, Noyes Data Corp, New Jersey, 1976.

[6] M. Antonijević, M. Petrović Mihajlović, Copper corrosion inhibitors. A review, International journal of electrochemical science 3 (1) (2008) 1-28.

[7] M. Petrović Mihajlović, M. Antonijević, Copper corrosion inhibitors. period 2008-2014. a review, International journal of electrochemical science 10 (2015) 1027-1053.

[8] M. M. Antonijević, S. M. Milić, M. B. Petrović, Films formed on copper surface in chloride media in the presence of azoles, Corrosion Science 51 (2009) 1228-1237.

[9] A. L. R. Silva, M. D. M. C. R. da Silva, Energetic, structural and tautomeric analysis of 2mercaptobenzimidazole, J. Therm. Anal. Calorim. 129 (3) (2017) 1679-1688.

[10] G. Form, E. Raper, T. Downie, The crystal and molecular structure of 2-mercaptobenzimidazole, Acta Crystallographica Section B: Structural Crystallography and Crystal Chemistry 32 (2) (1976) 345-348.

[11] D. Chadwick, T. Hashemi, Electron spectroscopy of corrosion inhibitors: Surface film formed by 2mercaptobenzothiazole and 2-mercaptobenzimidazole on copper, Surface Science 89 (1-3) (1979) 649659.

[12] G. Xue, X.-Y. Huang, J. Dong, J. Zhang, The formation of an effective anti-corrosion film on copper surfaces from 2-mercaptobenzimidazole solution, J. Electrounal. Chem. 310 (1991) 139-148.

[13] G. Xue, X. Huang, J. Ding, Surface reaction of 2-mercaptobenzimidazole on metals and its application in adhesion promotion, J. CHEM. SOC. FARADAY TRANS 87 (8) (1991) 1229-1232.

[14] G. Xue, Q. Dai, SERS and IR studies of the reaction of an oxidized surface and an etched surface of copper with 2-mercaptobenzimidazole, Spectroscopy Letters 27 (3) (1994) 341-351.

[15] B. Trachli, M. Keddama, H. Takenouti, A. Srhiri, Protective effect of electropolymerized 2mercaptobenzimidazole upon copper corrosion, Progress in Organic Coatings 44 (2002) 17-23.

[16] M. Finšgar, 2-mercaptobenzimidazole as a copper corrosion inhibitor: Part ii. surface analysis using X-ray photoelectron spectroscopy, Corrosion Science 72 (2013) 90-98.

[17] M. Finšgar, 2-mercaptobenzimidazole as a copper corrosion inhibitor: Part i. long-term immersion, 3D-profilometry, and electrochemistry, Corrosion Science 72 (2013) 82-89.

[18] F. Perrin, J. Pagetti, Characterization and mechanism of direct film formation on a $\mathrm{Cu}$ electrode through electro-oxidation of 2-mercaptobenzimidazole, Corrosion science 40 (10) (1998) 1647-1662.

[19] J. Izquierdo, J. J. Santana, S. González, R. M. Souto, Scanning microelectrochemical characterization of the anti-corrosion performance of inhibitor films formed by 2-mercaptobenzimidazole on copper, Progress in Organic Coatings 74 (3) (2012) 526-533.

[20] Y. Tooru, An X-ray photoelectron spectroscopic study of several metal complexes of 2mercaptobenzimidazole and 2-mercaptobenzoxazole, The Chemical Society of Japan 53 (5) (1980) 
1449-1450.

[21] M. G. HOSSEINI, T. SHAHRABI, R. J. NICHOLS, Characterization of mercaptobenzimidazole adsorption on an $\mathrm{Au}(111)$ electrode, Iranian Journal of Science \& Technology, Transaction A 29 (A1) (2005) 49-63.

[22] S. Sun, Y. Geng, L. Tian, S. Chen, Y. Yan, S. Hu, Density functional theory study of imidazole, benzimidazole and 2-mercaptobenzimidazole adsorption onto clean $\mathrm{Cu}(111)$ surface, Corrosion Science 63 (2012) 140-147.

[23] A. Kokalj, S. Peljhan, Density functional theory study of ATA, BTAH, and BTAOH as copper corrosion inhibitors: Adsorption onto $\mathrm{Cu}(111)$ from gas phase, Langmuir 26 (18) (2010) 14582-14593.

[24] N. Kovačević, I. Milošev, A. Kokalj, The roles of mercapto, benzene, and methyl groups in the corrosion inhibition of imidazoles on copper: Ii. inhibitor-copper bonding, Corrosion Science 98 (2015) 457-470.

[25] E. Vernack, D. Costa, P. Tingaut, P. Marcus, Theoretical studies of 2-mercaptobenzothiazole and 2-mercaptobenzimidazole as corrosion inhibitors for copper, Submitted to Corrosion Science (2020).

[26] X. Wu, F. Wiame, V. Maurice, P. Marcus, 2-mercaptobenzothiazole corrosion inhibitor deposited at ultra-low pressure on model copper surfaces, Corrosion Science (2020) 108464.

[27] X. Wu, F. Wiame, V. Maurice, P. Marcus, Adsorption and thermal stability of 2-mercaptobenzothiazole corrosion inhibitor on metallic and pre-oxidized $\mathrm{Cu}$ (111) model surfaces, Applied Surface Science 508 (2020) 145132 .

[28] T. Matsumoto, R. Bennett, P. Stone, T. Yamada, K. Domen, M. Bowker, Scanning tunneling microscopy studies of oxygen adsorption on $\mathrm{Cu}(111)$, Surface Science 471 (2001) 225-245.

[29] F. Wiame, V. Maurice, P. Marcus, Initial stages of oxidation of $\mathrm{Cu}(111)$, Surface Science 601 (2007) 1193-1204.

[30] R.W.Judd, P. Hollins, J. Pritchard, The interaction of oxygen with $\mathrm{Cu}(111)$ : Adsorption, incorporation and reconstruction, Surface Science 171 (1986) 643-653.

[31] I. Horcas, R. Fernández, J. M. Gómez-Rodríguez, J. Colchero, J. Gómez-Herrero, A. M. Baro, Wsxm: A software for scanning probe microscopy and a tool for nanotechnology, Review of Scientific Instruments 78 (2007) 013705.

[32] Casaxps manual 2.3.15, Casa Software Ltd (2009).

[33] L. Ruan, I. Stensgaard, F. Besenbacher, E. Laegsgaard, A scanning tunneling microscopy study of the interaction of $\mathrm{S}$ with the $\mathrm{Cu}(111)$ surface, Ultramicroscopy 42-44 (1992) 498-504.

[34] C. T. Campbell, B. E. Koel, $\mathrm{H}_{2} \mathrm{~S} / \mathrm{Cu}(111)$ : A model study of sulfur poisoning of water-gas shift catalysts, Surface Science 183 (1-2) (1987) 100-112.

[35] J. Jia, A. Kara, L. Pasquali, A. Bendounan, F. Sirotti, V. A. Esaulov, On sulfur core level binding energies in thiol self-assembly and alternative adsorption sites: An experimental and theoretical study, 
J. Chem. Phys. 143 (2015) 104702.

[36] M. Finšgar, D. K. Merl, An electrochemical, long-term immersion, and XPS study of 2mercaptobenzothiazole as a copper corrosion inhibitor in chloride solution, Corrosion Science 83 (2014) $64-175$.

[37] T. H. Fleisch, Reduction of copper oxides by UV radiation and atomic hydrogen studied by XPS, Applications of Surface Science 10 (1982) 51-62.

[38] F. Wiame, F.-R. Jasnot, J. Światowska, A. Seyeux, F. Bertran, P. L. Fèvre, A. Taleb-Ibrahimi, V. Maurice, P. Marcus, Oxidation of $\alpha$-brass: A photoelectron spectroscopy study, Surface Science 641 (2015) $51-59$.

[39] F. Wiame, V. Maurice, P. Marcus, Reactivity to sulphur of clean and pre-oxidised Cu(111) surfaces, Surface science 600 (18) (2006) 3540-3543. 